\title{
The Role of Ultrasound and Air Leak Measurement in Assessing Lung Expansion after Thoracic Surgery
}

\author{
Abraham Chavarín1, Laureano Molins, ${ }^{12 *}$, Jose M. Mier³, Juan J. Fibla1, \\ Cristina Izquierdo-Vidal ${ }^{2}$, Cristina Simon ${ }^{4}$, Angela Guirao ${ }^{1}$, Jorge Hernandez ${ }^{1}$ \\ ${ }^{1}$ Department of Thoracic Surgery, Hospital Universitari Sagrat Cor, Barcelona, Spain \\ ${ }^{2}$ Department of Thoracic Surgery, Hospital Clinic, Barcelona, Spain \\ ${ }^{3}$ Department of Thoracic Surgery, Instituto Nacional de Enfermedades Respiratorias, México D.F., México \\ ${ }^{4}$ Department of Radiology, Hospital Universitari Sagrat Cor, Barcelona, Spain \\ Email: Imolins@clinic.ub.es
}

Received 18 June 2015; accepted 27 July 2015; published 30 July 2015

Copyright (C) 2015 by authors and Scientific Research Publishing Inc.

This work is licensed under the Creative Commons Attribution International License (CC BY).

http://creativecommons.org/licenses/by/4.0/

(c) (i) Open Access

\section{Abstract}

Objective: To determine if lung ultrasound semiology is applicable to the post-surgical hemithorax, and its value in the evaluation of lung expansion in the postoperative period when paired with the use of digital chest drain systems. Methods: Prospective observational study including all patients undergoing thoracic surgery from June 2012 to March 2013. Patients undergoing pleurodesis or hemodynamically unstable were not considered candidates. Final inclusion in the study was based on the availability of digital chest drain system. A transthoracic lung ultrasound evaluation of the anterior and anterolateral windows was performed 20 minutes after chest drain placement. Presence or not of lung sliding and air leak values taken from the digital chest drain system were recorded. Data were submitted to a binomial classification test for analysis. Results: Forty-nine patients were included, yielding a total of 64 hemithoraces. Lung sliding was seen in 53 cases $(82.8 \%)$, and an air leak value of $20 \mathrm{ml} / \mathrm{min}$ or less in 56 cases $(87.5 \%)$. Sensitivity was $92.8 \%(95 \%$ CI: $82.6 \%$ to $97.9 \%$ ) and specificity $87.5 \%$ (95\% CI: $47.3 \%$ to $97.9 \%$ ). Positive predictive value was $98.1 \%$, and negative predictive value was $63.6 \%$. Conclusions: Transthoracic lung ultrasound is a useful technique that can complement the use of digital chest drain systems in the evaluation of post-surgical lung expansion. The incorporation of lung ultrasound can greatly reduce the need for chest radiographs in thoracic surgery departments.

\section{Keywords}

Thoracic Surgery, Pneumothorax, Ultrasonography, Lung Expansion, Chest Radiograph

\footnotetext{
${ }^{*}$ Corresponding author.
}

How to cite this paper: Chavarín, A., Molins, L., Mier, J.M., Fibla, J.J., Izquierdo-Vidal, C., Simon, C., Guirao, A. and Hernandez, J. (2015) The Role of Ultrasound and Air Leak Measurement in Assessing Lung Expansion after Thoracic Surgery. Surgical Science, 6, 352-357. http://dx.doi.org/10.4236/ss.2015.68052 


\section{Introduction}

With the publication of the BLUE protocol [1]—Bedside Lung Ultrasound Evaluation—a lung ultrasound semiology has been consolidated. Concepts like the "seashore sign" (lung sliding) shown in Figure 1, or the "stratosphere sign” shown in Figure 2 (pneumothorax) are becoming mainstream in many emergency medicine and intensive care units that use lung ultrasound in patient evaluation. The visualization of lung sliding is the basic principle in lung ultrasound. The pleural line is the image formed by the two pleurae in contact with each other. Lung sliding is the sparkling movement of the pleural line with ventilatory movements. In 1995, Lichtenstein et al. [2], demonstrated that lung sliding was absent in $100 \%$ of pneumothoraces. Galbois et al. [3] proved in their series that lung ultrasound was more effective than conventional chest X-rays in the diagnosis of residual pneumothorax. When compared with a computer aided tomography scan, lung ultrasound identified $100 \%$ of residual pneumothorax while chest X-ray only detected 61\%. Our aim is to determine if lung ultrasound is applicable in post-surgical thorax and its value in the evaluation of lung expansion in a post-operative care setting.

\section{Patients and Methods}

This is a prospective observational study including patients undergoing thoracic surgery in the period from June 2012 to March 2013. In all the patients a digital chest drain system was employed. The work was conducted in compliance with our Institutional Review Board and Human Subjects Research Committee requirements. Informed written consent was obtained in pre-surgical evaluation in all cases that were considered to meet inclusion criteria. In order to obtain $95 \%$ confidence intervals with a range of \pm 3 , and $80 \%$ power calculations a minimum sample size of 60 hemithoraces was required.

Patients with hemodynamic instability were excluded as well as patients that underwent pleurodesis. A transthoracic lung ultrasound evaluation of the anterior (second intercostal space at the midclavicular line) and the anterolateral (fourth or fifth intercostal space at the anterior axillary line) wall was performed 20 minutes after chest drain placement. These particular windows were preferred due to the presence of surgical wound dressings in most cases. The presence ("seashore sign” Figure 1) or absence ("stratosphere sign" Figure 2) of

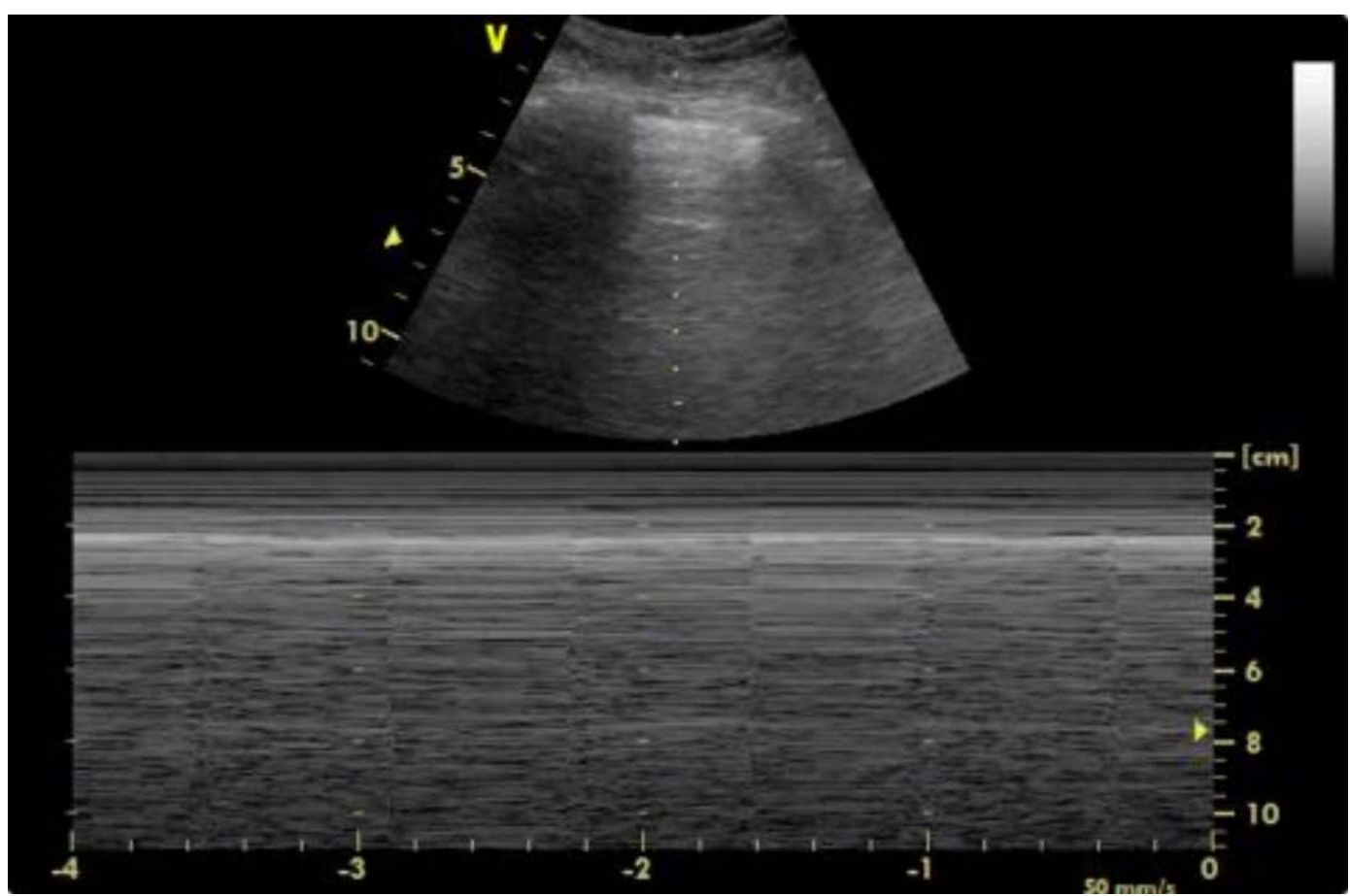

Figure 1. Seashore sign. The pleural line is the image formed by the two pleurae in contact with each other. This sign is a normal finding of lung sliding. In absence of a seashore sign or presence of a stratosphere sign, pneumothorax is likely. 


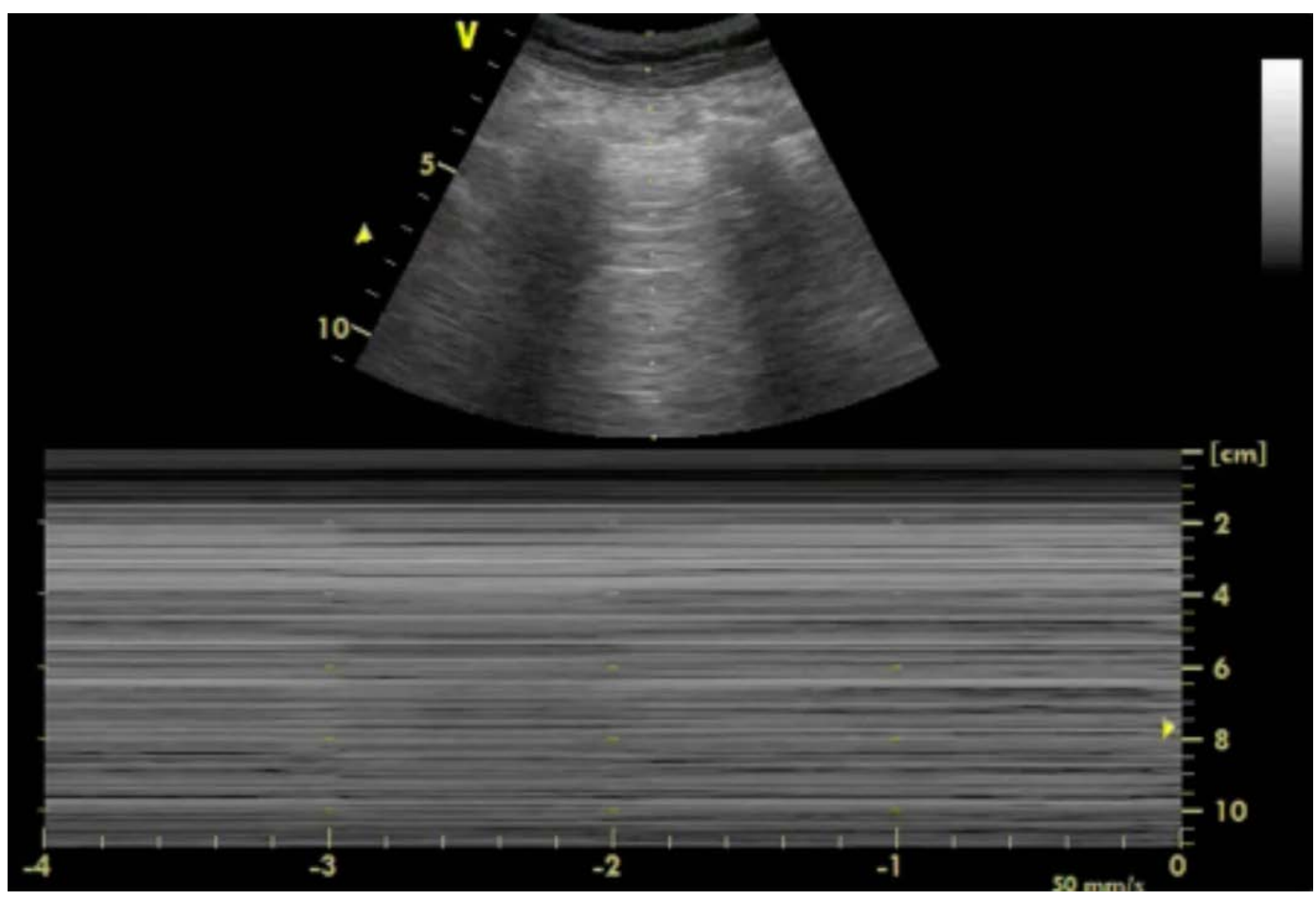

Figure 2. Stratosphere sign. Pleura and lung are indistinguishable as linear hyperechogenic lines. This sign is fairly reliable for diagnosis of a pneumothorax (absence of lung expansion).

lung sliding was recorded. The absence of lung sliding in either window was considered a pneumothorax. A digital chest drain system measurement was registered at the time of the evaluation. Digital air leak measurements of $20 \mathrm{ml} / \mathrm{min}$ or less were considered as fully expanded and deemed for chest drain removal if no other indication for a chest drain was present (i.e. effusion, discharge, promptness). In all cases, a digital chest X-ray was obtained at a later time, and standard chest drainage management procedure was followed. Data were analyzed as a single group and then divided into two sub-groups based on the type of procedure performed: mainly pulmonary surgery and non-pulmonary surgery. All data collected were submitted to a binomial classification test for analysis. Continuous quantitative values were expressed as means. Sensitivity and specificity were calculated as appropriate and 95\% confidence interval (CI) was included for statistical comparison.

\section{Results}

A sample of 50 patients was obtained. One case had to be excluded due to digital chest drain malfunction. The remaining sample consisted of 49 patients ( 37 male/12 female), with a mean age of 45.75 years. It yielded a total of 64 hemithoraces for study as bilateral procedures were counted as independent procedures (Table 1).

In the evaluation of the full sample ( $\mathrm{n}=64)$, lung sliding was found in 53 cases $(82.8 \%)$, and an air leak value of $20 \mathrm{ml} / \mathrm{min}$ or less was seen in 56 cases (87.5\%). Sensitivity was $92.8 \%$ (95\% CI: 82.6\% to 97.9\%) and specificity $87.5 \%$ (95\% CI: $47.3 \%$ to $97.9 \%$ ). Positive predictive value was $98.1 \%$ and Negative predictive value $63.6 \%$ (Table 2, and Table 3).

\subsection{Non-Pulmonary Surgery}

This group included 35 hemithoraces, procedures included are listed in Table 1. Lung sliding was found in $35 / 35$ (100\%). Digital air leak of $20 \mathrm{ml} / \mathrm{min}$ or less was present in $100 \%$ of cases (35/35). Sympathectomy and sympathectomy reversal patients were also analyzed as a separate subgroup $(n=29)$ as these cases were part of our out-patient surgical unit and chest X-ray was available within 25 minutes after digital chest drain placement. Full lung expansion was found in 29/29 (100\%) of the X-rays, lung sliding was present in 29/29 cases (100\%) and a digital air leak measurement of $20 \mathrm{ml} / \mathrm{min}$ or less was found in 29/29 hemithoraces (100\%). 
Table 1. Demographics and patients.

\begin{tabular}{lc}
\hline Characteristic & Value \\
\hline Number of patients & 49 \\
Number of hemithoraces & 64 \\
Gender, $\mathrm{n}(\%)$ & $37(75.5 \%)$ \\
Male & $12(24.5 \%)$ \\
Female & $45.7(12)$ \\
Age, mean (SD) & 35 \\
Non-pulmonary procedures by type, $\mathrm{n}$ & 27 \\
Sympathectomy & 3 \\
Thymomas & 2 \\
Mediastinal tumors & 2 \\
Sympathectomy reversal & 1 \\
Pleural nodule & 29 \\
Pulmonary procedures by type, $\mathrm{n}$ & 11 \\
VATS, left wedge resection & 9 \\
VATS, right wedge resection & 3 \\
Lobectomy, left & 3 \\
Lobectomy, right & 1 \\
Mid sternotomy, right nodule & 2 \\
Pneumothorax & \\
\end{tabular}

Table 2. Total number of diagnostic examinations.

\begin{tabular}{cccc}
\hline & True positive & True negative & False positive \\
\hline Total sample & 52 & 7 & 1 \\
Pulmonary procedures & 17 & 7 & 1 \\
\hline
\end{tabular}

Table 3. Evaluation of lung sliding.

\begin{tabular}{|c|c|c|}
\hline Variables & Total sample & Pulmonary procedures \\
\hline $\begin{array}{l}\text { Sensitivity } \\
\%(95 \% \mathrm{CI})\end{array}$ & $92.8 \%(82.9,97.8)$ & $80.5 \%(58.8,94.4)$ \\
\hline $\begin{array}{l}\text { Specificity } \\
\%(95 \% \text { CI })\end{array}$ & $87.5 \%(47.3,97.9)$ & $87.5 \%(47.3,97.9)$ \\
\hline $\begin{array}{c}\text { Disease prevalence } \\
\%(95 \% \mathrm{CI})\end{array}$ & $87.5 \%(76.8,94.4)$ & $72.4 \%(52.7,87.2)$ \\
\hline $\begin{array}{c}\mathrm{PPV} \\
\%(95 \% \mathrm{CI})\end{array}$ & $98.1 \%(89.9,99.6)$ & $94.4 \%(72.6,99.0)$ \\
\hline $\begin{array}{c}\text { NPV } \\
\%(95 \% \mathrm{CI})\end{array}$ & 63.6\% $(30.8,88.8)$ & $63.6 \%(30.8,88.8)$ \\
\hline
\end{tabular}

PPV = Predictive Positive Value; NPV = Negative Predictive Value.

\subsection{Pulmonary Surgery}

Twenty-nine hemithoraces were evaluated. Lung sliding was present in 18 cases (62\%). Digital air leak value of $20 \mathrm{ml} / \mathrm{min}$ or less was found in 21 cases (72\%). Inter-rate agreement (Weighted Kappa) was 0.61. Sensitivity was $80.9 \%$ (95\% CI: $58.0 \%$ to $94.4 \%$ ), and specificity $87.5 \%$ (95\% CI: $47.3 \%$ to 97.9\%). Positive and negative predictive values were $94.4 \%$ (95\% CI: $72.6 \%$ to $99.0 \%$ ) and $63.6 \%$ (95\% CI: 30.8\% to $88.8 \%$ ) respectively (Table 3).

\section{Discussion}

Lung ultrasound has been proven to be almost as accurate as CT scanning in detecting the presence of pneu- 
mothorax [4] occult pneumothorax and its extension [5]. In the present study and after analyzing 49 patients (64 hemothoraces) we found that ultrasound had a sensitivity of $92.8 \%$, a specificity of $87.5 \%$, a positive predictive value of $98.1 \%$, and a negative predictive value of $63.6 \%$. Our results showed that lung sliding is a good indicator of lung expansion, especially when paired with digital air leak measurements. After analyzing our results we found out that the addition of lung ultrasound evaluation showing lung sliding sign and a digital air leak value of $20 \mathrm{ml} / \mathrm{min}$ or less in non-pulmonary surgery patients allows a safe exclusion of pneumothorax.

The results found in our sympathectomy sub-group were identical to those published by Saucier et al. [6], who reported a perfect agreement between lung ultrasound and chest radiography to detect pneumothorax in a series of 50 cardiothoracic surgery patients.

Our results were also comparable to those found by Shostak E. et al. [7] in a similar study but with minor procedures. They performed transthoracic ultrasound in a series of 185 patients submitted to thoracentesis, transbronchial biopsy and computed tomography-guided needle lung biopsy. The sensitivity and specificity were $88 \%$ and $97 \%$ respectively.

However, not all the studies have found an optimal accuracy of ultrasound evaluation in the detection of lung expansion. Goudie et al. [8] in a prospective cohort trial of 120 patients submitted to thoracic surgery and bedside postoperative ultrasound evaluation, found a sensitivity and specificity in the detection of postoperative pneumothorax of $21.2 \%$ and $94.7 \%$. They justified the low sensitivity arguing that postoperative inflammation within the pleural cavity could affect the interpretations of ultrasonographic findings indicative of a pneumothorax. It is accepted that postoperative pleural inflammation makes more difficult to detect pneumothorax, however we believe that with an adequate training this should not become a problem. Surgeons performing echography in Goudi et al. al study did not have a large experience in echography, indeed they had an intensive 2week training period focused on basic chest ultrasound. We believe this is enough training to detect pleural effusions but not sufficient for a high accuracy in detecting lung expansion following thoracic surgery. A longer training is adviced for this purpose - of 1 month at least.

Digital chest drain systems are considered superior to traditional water seal devices and its use is extending [9]. However there is not such a consensus regarding ultrasound benefits in thoracic surgery patients. Different studies have been published proving bedside ultrasound is a valuable tool in the management of these patients [7] [10]-[16], meanwhile other authors have warned about the limitations of the technique [8] [17]-[20].

To our knowledge the present study is the first one demonstrating a high accuracy of bedside ultrasound evaluation combined with digital chest drain systems in the detection of postoperative lung expansion.

Our study has limitations. It is a prospective cohort with a limited number of patients. In the Pulmonary surgery group, we found that the absence of lung sliding can coexist with digital air leak values of $20 \mathrm{ml} / \mathrm{min}$ or less. This anomalous situation can be explained by the following: a. Resection volume and site, and b. irregular compensatory lung expansion. Video Assisted Thoracoscopic (VAT) wedge resections do not follow a strict anatomic pattern making compensatory lung expansion less predictable. Larger resections have increased the probability of the probe being placed directly over the resected area thus leading to a false image of pneumothorax. The presence of an air leak value of $20 \mathrm{ml} / \mathrm{min}$ or less in these cases supports the fact that it is an anatomical defect of the lung rather than a pneumothorax that yields the false negative result in the ultrasound evaluation.

\section{Conclusion}

Bedside trans-thoracic ultrasound evaluation combined with a digital chest drain system has the potential to be effective and convenient in the detection of lung expansion after thoracic surgery. Future prospective randomized studies are warranted to confirm these findings and determine whether this postoperative management policy is able to minimize the use of postoperative chest X-rays.

\section{References}

[1] Lichtenstein, D.A. and Meziere, G.A. (2008) Relevance of Lung Ultrasound in the Diagnosis of Acute Respiratory Failure: The BLUE Protocol. Chest, 134, 117-125. http://dx.doi.org/10.1378/chest.07-2800

[2] Lichtenstein, D.A. and Menu, Y. (1995) A Bedside Ultrasound Sign Ruling out Pneumothorax in the Critically Ill. Lung Sliding. Chest, 105, 1345-1348. http://dx.doi.org/10.1378/chest.108.5.1345

[3] Galbois, A., Ait-Oufella, H., Baudel, J.L., Kofman, T., Bottero, J., Viennot, S., et al. (2010) Pleural Ultrasound Compared with Chest Radiographic Detection of Pneumothorax Resolution after Drainage. Chest, 128, 648-655. 
http://dx.doi.org/10.1378/chest.09-2224

[4] Saucier, S., Motyka, C. and Killu, K. (2010) Ultrasonography versus Chest Radiography after Chest Tube Removal for the Detection of Pneumothorax. AACN Advanced Critical Care, 21, 34-38. http://dx.doi.org/10.1097/NCI.0b013e3181c8013a

[5] Ahston-Cleary, D.T. (2013) Is Thoracic Ultrasound a Viable Alternative to Conventional Imaging in the Critical Care Setting? British Journal of Anaesthesia, 111, 152-160. http://dx.doi.org/10.1093/bja/aet076

[6] Soldati, G., Testa, A., Sher, S., Pignataro, G., La Sala, M. and Silveri, N.G. (2008) Occult Traumatic Pneumothorax: Diagnostic Accuracy of Lung Ultrasonography in the Emergency Department. Chest, 133, 204-211. http://dx.doi.org/10.1378/chest.07-1595

[7] Shostak, E., Brylka, D., Krepp, J., Pua, B. and Sanders, A. (2013) Bedside Sonography for Detection of Postprocedure Pneumothorax. Journal of Ultrasound in Medicine, 32, 1003-1009. http://dx.doi.org/10.7863/ultra.32.6.1003

[8] Goudie, E., Bah, I., Khereba, M., Ferraro, P., Duranceau, A., Martin, J., Thiffault, V. and Liberman, M. (2012) Prospective Trial Evaluating Sonography after Thoracic Surgery in Postoperative Care and Decision Making. European Journal of Cardio-Thoracic Surgery, 41, 1025-1030. http://dx.doi.org/10.1093/ejcts/ezr183

[9] Pompili, C., Detterbeck, F., Papagiannopoulos, K., Sihoe, A., Vachlas, K., Maxfield, M.W., Lim, H.C. and Brunelli, A. (2014) Multicenter International Randomized Comparison of Objective and Subjective Outcomes between Electronic and Traditional Chest Drainage Systems. Annals of Thoracic Surgery, 98, 490-496. http://dx.doi.org/10.1016/j.athoracsur.2014.03.043

[10] Lisi, M., Cameli, M., Mondillo, S., Luzzi, L., Zaca, V., Cameli, P., et al. (2012) Incremental Value of Pocket-Sized Imaging Device for Bedside Diagnosis of Unilateral Pleural Effusions and Ultrasound-Guided Thoracentesis. Interactive Cardiovascular and Thoracic Surgery, 15, 596-601. http://dx.doi.org/10.1093/icvts/ivs223

[11] Peris, A., Tutino, L., Zagli, G., Batacchi, S., Cianchi, G., Spina, R., et al. (2010) The Use of Point-of-Care Bedside Lung Ultrasound Significantly Reduces the Number of Radiographs and Computed Tomography Scans in Critically Ill Patients. Anesthesia \& Analgesia, 111, 687-692. http://dx.doi.org/10.1213/ANE.0b013e3181e7cc42

[12] Lavingia, K.S., Soult, M.C., Collins, J.N., Novosel, T.J., Weireter, L.J. and Britt, L.D. (2014) Basic Ultrasound Training Can Replace Chest Radiography for Safe Tube Thoracostomy Removal. The American Surgeon, 80, 783-786.

[13] Soult, M.C., Collins, J.N., Novosel, T.J., Weireter, L.J. and Britt, L.D. (2014) Thoracic Ultrasound Can Predict Safe Removal of Thoracostomy Tubes. Journal of Trauma and Acute Care Surgery, 77, 256-261. http://dx.doi.org/10.1097/TA.0000000000000315

[14] Andruszkiewicz, P. and Sobczyk, D. (2013) Ultrasound in Critical Care. Anestezjologia Intensywna Terapia, 45, 177181. http://dx.doi.org/10.5603/AIT.2013.0036

[15] Kwan, R.O., Miraflor, E., Yeung, L., Strumwasser, A. and Victorino, G.P. (2012) Bedside Thoracic Ultrasonography of the Fourth Intercostal Space Reliably Determines Safe Removal of Tube Thoracostomy after Traumatic Injury. Journal of Trauma and Acute Care Surgery, 73, 1570-1575. http://dx.doi.org/10.1097/TA.0b013e318265fc22

[16] Abbasi, H.R., Salahi, R., Paydar, S., Johari, H.G. and Bolandparvaz, S. (2011) Is Routine Chest X-Ray Necessary before Chest Tube Removal? The Journal of Trauma, 70, 523. http://dx.doi.org/10.1097/TA.0b013e318206d2bd

[17] Sperandeo, M., Maggi, M., Catalano, D. and Trovato, G. (2014) No Sliding, No Pneumothorax: Thoracic Ultrasound Is Not an All-Purpose Tool. Journal of Clinical Anesthesia, 26, 425-426. http://dx.doi.org/10.1016/j.jclinane.2014.04.005

[18] Rea, G., D’Amato, M. and Ghittoni, G. (2014) Pitfalls of the Ultrasound Diagnosis of Pneumothorax. The American Journal of Emergency Medicine, 32, 1126-1127. http://dx.doi.org/10.1016/j.ajem.2014.03.053

[19] Cavaliere, F., Zamparelli, R., Soave, M.P., Gargaruti, R., Scapigliati, A. and De Paulis, S. (2014) Ultrasound Artifacts Mimicking Pleural Sliding after Pneumonectomy. Journal of Clinical Anesthesia, 26, 131-135. http://dx.doi.org/10.1016/j.jclinane.2013.09.011

[20] Eisenhuber, E., Schaefer-Prokop, C.M., Prosch, H. and Schima, W. (2012) Bedside Chest Radiography. Respiratory Care, 57, 427-443. http://dx.doi.org/10.4187/respcare.01712 